Journal of the Scholarship of Teaching and Learning, Vol. 20, No. 1, April 2020, pp.40-64.

doi: $10.14434 /$ josotl.v20i1.24688

\title{
Diverse Student Perceptions of Active Learning in a Large Enrollment STEM Course
}

\author{
Benikia Kressler \\ California State University, Fullerton \\ bkressler@,fullerton.edu \\ Jochen Kressler \\ San Diego State University
}

\begin{abstract}
The concept of active learning as a superior mode of instruction has recently received great attention in the education research literature. It holds promise of steering students away from rote memorization towards higher order thinking (as defined by Bloom's taxonomy revised). However, few studies focus on student perceptions of higher order thinking activities and diverse student voices are all but absent in this regard. This study applies a combined approach of exploratory qualitative and supplementary quantitative analysis to address this gap. We examined perceptions of underrepresented and non-underrepresented students regarding their engagement in active learning to foster higher order thinking. The study was set within a large enrollment (198 students), undergraduate course in the area of science, technology, engineering and mathematics (STEM). The study sample comprised of 33 purposefully selected, ethnically and racially diverse students. Data sources included class attendance/participation, graded activity assignments, and a perception survey. Class attendance and graded assignments were used to triangulate responses on the perception surveys. The Generic Inductive Approach supported our qualitative analysis. Quantitative data were analyzed via two-way ANOVA, non-parametric Mann-Whitney Test (when assumptions did not hold) and simple linear regression. Findings include three themes that cut across groups; participants perceived their higher order thinking skills improved, that there were benefits and challenges to active learning and a fear of failing the course. Quantitative data from the active learning activities and attendance supported similar engagement and achievement in higher order thinking activities across race/ethnicity groups as differences failed to reach the a priori established significance threshold. This study extends the knowledge on active learning and demonstrates that it was possible to engage underrepresented and non-underrepresented students equally and effectively in bigher order thinking actives in large enrollment courses and that students perceived this as beneficial.
\end{abstract}

Keywords: higher order thinking, active learning, STEM, student perceptions, critical thinking

The dreams, possibilities, and necessity of public education extends beyond K-12 systems. In higher education, educators must provide high quality and meaningful education to all students. This includes using research supported strategies that support the academic achievement of students typically underrepresented in higher education with diverse backgrounds. This study acknowledges this charge by examining student perceptions of their engagement in active learning activities that support higher order thinking (as defined by Bloom's taxonomy revised, (Anderson et al., 2001) within a large enrollment undergraduate course in the area of science, technology, engineering and mathematics (STEM).

Engaging in active learning strategies that support higher order thinking within higher education settings are considered best practices in educational literature (Bonwell \& Eison, 1991; Casagrand \& Semsar, 2017; Freeman et al., 2014; Sellami et al., 2017, White et al., 2016). Specifically, 
providing undergraduate students the opportunity to engage in complex course material using student centered, collaborative, multimodal techniques significantly increases student learning when compared to standard lecture (LoPresto \& Slater, 2016). Examples of active learning include cooperative group activities, in-class worksheets, clickers, problem-based learning, and studio classrooms (Freeman et al., 2014).

Actively engaging students in large enrollment courses, specifically science, technology, engineering and mathematics (STEM) courses, is particularly important given the heavy cognitive load of the work, student failure rate and the tendency for rote memorization to study for tests (Biggs, 2011; Bligh, 1998; Gasiewski et al., 2012). Further, today's job market calls for $21^{\text {st }}$ century skills that include ability to communicate, collaborate, think critically and be creative (Dede, 2010). It is imperative to arm students with $21^{\text {st }}$ century skills to prepare them for entrance into one of the most competitive and diverse economic markets to date (Ali, 2017; Casner-Lotto \& Barrington, 2006; Dede, 2010; Ghaffarzadegan et al., 2014; Maddux et al., 2014; Saavedra \& Opfer, 2012). Consequently, this study examines student perceptions of their engagement in active learning within a large enrollment undergraduate course in a STEM course.

\section{Literature Review}

Many university instructors accept the notion that involving students in cognitive processing activities is more effective than instructor-led lectures (Dunkin, 1983; Eichler \& Peeples, 2016; Mayer et al., 2009). The work of Freeman et al., (2014) (Freeman et al., 2014) provides strong scientific evidence in favor of active learning strategies over lecture-based instruction, at least at the undergraduate level in STEM disciplines. In a comprehensive meta-analysis of 158 randomized, controlled trials Freeman et al. 2014 (Freeman et al., 2014) reports that student performance (as assessed by examinations or concept inventories) improved by 0.5 SDs in active learning vs. lecture control. This effect is even larger for class sizes with 50 students or less, and the meta-analysis did not extend beyond common STEM fields (Freeman et al., 2014). In addition, sub-analysis of 67 studies found that the odds ratio for failing a course was almost twice as high (1.95) for lecture conditions. This Tier 1 (Harris et al., 2001) evidence clearly demonstrates the effectiveness of active learning for all students, including those with high risk of failure.

Critics posit that undergraduates in STEM are not receiving sufficient instruction (Bok, 2009; Stains, 2018). This critique has not been ignored. Active learning practices have gained traction within institutions of higher education. However, it has been a slow process. Studies show that $65 \%$ to $80 \%$ of university instructors continue to engage in teacher centered learning (i.e., lecturing) (Nelson \& Crow, 2014).

There are many reasons that explain this discrepancy between the scientific evidence and incorporation of best practices into actual practice. There is a general lack of resources in support of pedagogical development with STEM disciplines (Baldwin, 2009; George \& Bragg, 1996). Incentive structures usually do not reward instructors to study the pertinent literature regarding teaching and learning or to put extensive time and effort into improving the way they deliver courses to students (Baldwin, 2009; George \& Bragg, 1996; National Research Council, 2003; Wieman, 2007). If teaching effectiveness is considered, universities mostly rely on student evaluations of teaching (SETs) which at best have no correlation to teaching effectiveness and at worst, can promote practices that are counterproductive (Braga et al., 2014; Carrell \&West, 2010; Dunkin, 1990; Kornell \& Hausman, 2016; Uttl et al., 2017). SETs may also reinforce many instructor's falsely held believes about their own teaching effectiveness and thereby obscure the need for a change in their teaching approach (Mazur, 2011). Indeed, fear of negative evaluations following substantial changes to teaching methodology causes many faculty to be reluctant to change (Eichler \& Peeples, 2016; Ryan et al., 1980) because exposing students to a drastically different learning environment can result

Journal of the Scholarship of Teaching and Learning, Vol. 20, No. 1, April 2020.

josotl.indiana.edu 
in decreased satisfaction (Eichler \& Peeples, 2016; Gutwill-Wise, 2001). In addition, there is a lack of institutional commitment to developing, implementing and supporting research based teaching across a wide range of STEM courses (Wieman, 2007). Lastly, there are simple physical impediments. Many undergraduate STEM classes take place in large lecture halls constraining instructional practices through room architecture and seating arrangements (Baldwin, 2009).

This is of course extremely problematic because research show that lecture only approach is not effective for most students (Freeman et al., 2014; Wieman, 2007; Zoller, 1993), and is particularly ineffective for underrepresented students in large lecture classes with a reputation for high failure rates (Haak et al., 2011; Hrabowski, 2011; Mervis, 2010; Mulligan, 2000). Underrepresented and underserved students in college include Black, Hispanic, Native American and Pacific Islanders as well as first generation college students. These groups are less likely to complete four-year degree programs as White and Asian peers (US Department of Education, 2014). In addition, students in high failure courses are dissatisfied with the quality of STEM teaching, particularly when size limits student-teacher dialogue (Baldwin, 2009). Improving the persistence of underrepresented college students typically focus on advising, scholarships and tutoring with limited studies examining classroom based strategies (Winkelmes, Bernacki, Butler, Zochowski, Golanics \& Weavil, 2016). Although limited, a study by Winkelmes (2013) found transparency regarding how college students learn, what they learn and why a course is structured a particular way "showed promise for improving underserved students' educational experiences" (p.1). Another study found that students perceived "technology-nested" instructional strategies as a strong component to content engagement and enjoyment (Lumpkin, Achen \& Dodd, 2015 p. 12). These studies highlight the promise of explicit instruction or transparency and using technology in college courses for all students.

While active learning is more effective, problems can arise when student's perception of active leaning techniques become negative over time as the novelty wears off over the course of a semester (McDougall, 2013; Nguyen et al., 2016; Cooper, Downing, Brownell, 2018). The limited discussion of student perception in the literature reports that students perceive in-class activity as effective but did not specifically assess perceptions of higher order thinking (Nail, 2012; Nguyen et al., 2016). Certain types of active learning strategies such as using case studies and creative activities can be applied to pertinent situations to support higher order thinking (Bean, 2011). However, students in active learning environments resented the "intellectual effort" needed for successful completion of activities (Smith \& Cardaciotto, 2012). Evidently, activities targeting higher order thinking require the most intellectual effort. This presents a stark contrast to the standard lecture format which encourages students to be mostly passive learners (National Research Council, 2003) who rely heavily on the lower levels of thinking such as memorization of facts or formulas (Baldwin, 2009; Brainard, 2007; National Research Council, 2003). Whether there are differences in the perception of active learning to support higher order thinking among underrepresented students is currently unknown.

Therefore, the purpose of this study was to examine both underrepresented and nonunderrepresented student perceptions of collaborative, active learning activities that support higher order thinking in a large enrollment STEM course. The overarching research questions guiding this study are: "What are underrepresented and non-underrepresented students perceptions of active learning activities within a large lecture course?", "What are underrepresented and nonunderrepresented student perceptions of their higher order thinking skills after engaging in the course?" and "Are there differences in these perceptions?".

Journal of the Scholarship of Teaching and Learning, Vol. 20, No. 1, April 2020.

josotl.indiana.edu 


\section{Methods}

This exploratory mixed methods study (Creswell et al., 2003) was drawn from a larger IRB approved research project. This study consisted of a sample of 33 students from a large (198 students), upper division (juniors and seniors) undergraduate, health science course at a major public university located on the west coast of the United States during Spring 2016. The sampled participants included 19 females and 14 males. Age ranged from 20-29 years. The sample was ethnically and racially diverse. Eleven Asian, Hispanic and White students were purposefully selected (Patton, 2015) as they represented the larger racial makeup of the course. ${ }^{1}$ We focused on the three largest racial/ethnic groups in the course. Students self-identified their race/ethnicity and then were randomly selected within each group. Table 1 illustrates student identification in greater detail as well as other demographic information.

Table 1: Subject Demographics

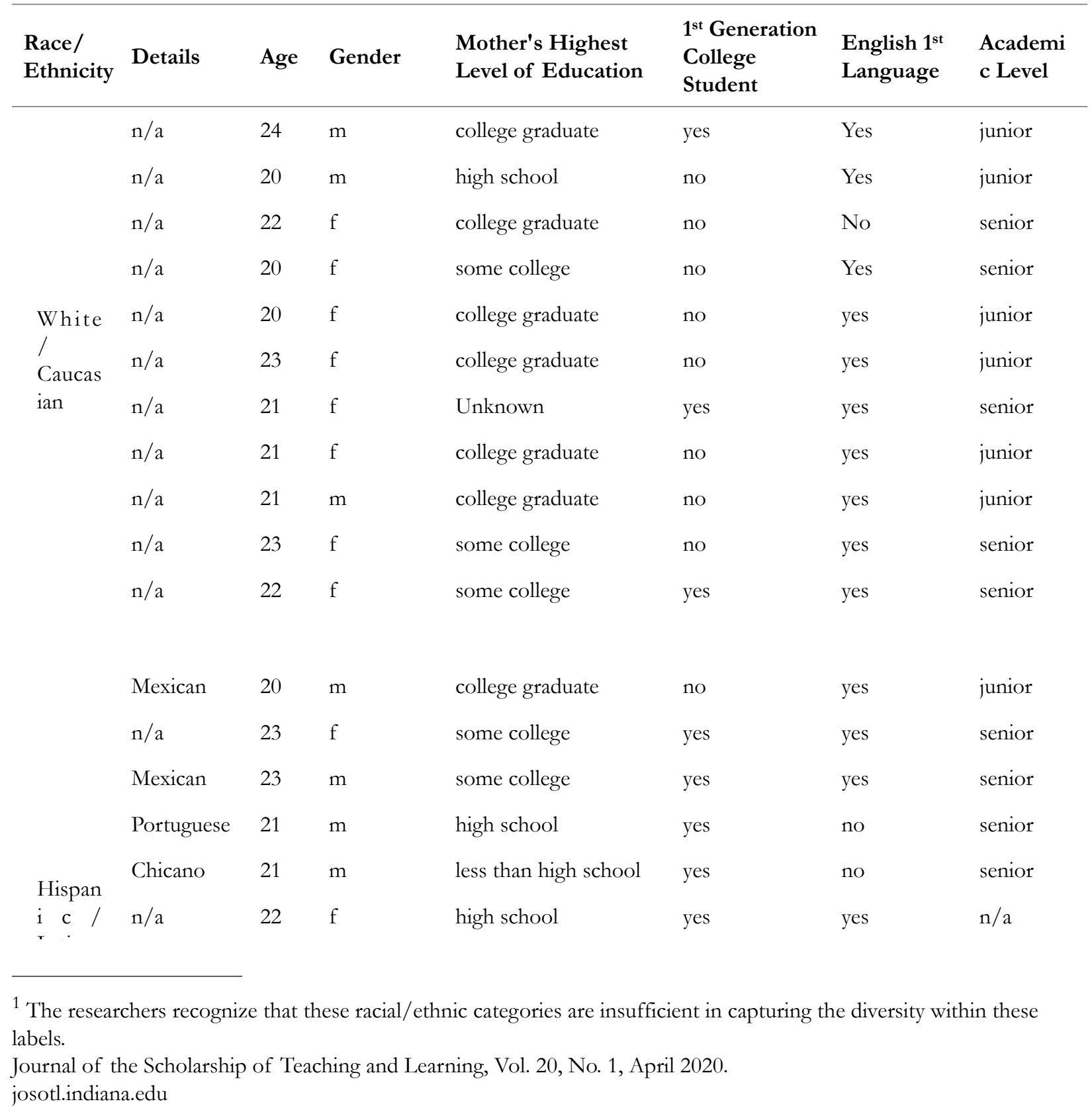


Latinx

$\begin{array}{lllllll}\mathrm{n} / \mathrm{a} & 24 & \mathrm{~m} & \text { college graduate } & \text { no } & \text { yes } & \text { junior } \\ \text { Mexican } & 21 & \mathrm{f} & \text { some college } & \text { no } & \text { yes } & \text { junior } \\ \mathrm{n} / \mathrm{a} & 22 & \mathrm{~m} & \text { some college } & \text { no } & \text { yes } & \text { senior } \\ \mathrm{n} / \mathrm{a} & 22 & \mathrm{~m} & \text { college graduate } & \text { no } & \text { no } & \text { senior } \\ \mathrm{n} / \mathrm{a} & 20 & \mathrm{f} & \text { high school } & \text { yes } & \text { yes } & \text { junior }\end{array}$

\begin{tabular}{|c|c|c|c|c|c|c|c|}
\hline & Filipino & 21 & $\mathrm{f}$ & college graduate & no & yes & senior \\
\hline & $\mathrm{n} / \mathrm{a}$ & 21 & $\mathrm{f}$ & high school & yes & yes & junior \\
\hline & Thai & 22 & $\mathrm{~m}$ & some college & yes & no & senior \\
\hline & $\mathrm{n} / \mathrm{a}$ & 23 & $\mathrm{~m}$ & some college & no & yes & senior \\
\hline & Japanese & 22 & $\mathrm{~m}$ & some college & yes & no & junior \\
\hline Asian & $\mathrm{n} / \mathrm{a}$ & 20 & $\mathrm{~m}$ & college graduate & no & yes & junior \\
\hline & Chinese & 20 & $\mathrm{f}$ & less than high school & yes & no & junior \\
\hline & Filipino & 20 & $\mathrm{f}$ & high school & no & yes & junior \\
\hline & Filipino & 21 & $\mathrm{f}$ & college graduate & yes & yes & senior \\
\hline & Filipino & 23 & $\mathrm{f}$ & some college & no & yes & $\mathrm{n} / \mathrm{a}$ \\
\hline & Filipino & 29 & $\mathrm{~m}$ & college graduate & no & yes & junior \\
\hline
\end{tabular}

\section{Course Description}

The course for this study was Measurement and Evaluation in Kinesiology (ENS 305). This course is required for all emphases within the Kinesiology major, the largest major at the university $(1,800$ students, $>5 \%$ of total undergrad enrollment) and part of the second largest field for undergraduate degrees conferred in the United States (National Center for Education Statistics, 2016). Other common names of this major include Exercise Science, Physical Education, Exercise and Sport Science, Health and Exercise Science, Exercise Science and Wellness, Exercise and Fitness, Kinesiological Sciences, and Exercise Physiology (Boone, 2000).

This course was chosen to be redesigned with a focus on technology and active collaborative learning to support student achievement. In previous semesters $20 \%$ of grades fell into the repeatable category. It has recently been the main bottleneck course leading to delays for students trying to advance through the major, impacting four year and six year graduation rates. The course builds on prerequisite statistics courses by using descriptive and inferential statistics to examine the quality of assessment tools, study designs and inferential analysis used by Exercise Science and Kinesiology professionals. The emphasis of the class is on the active use of higher order thinking skills to apply assessment principles for the determination of the quality of assessment tools and usefulness of the data for meaningful decision-making. The concepts of higher order thinking according to boom's taxonomy were explained to students on the first day of class (the only day with mandatory attendance), and students were reminded and made aware of what type of thinking they were expected to perform for the activities. The course met twice a week for one hour and 15 minutes each session.

Journal of the Scholarship of Teaching and Learning, Vol. 20, No. 1, April 2020. 
Five graduate assistants (GAs) helped facilitate the active learning in class environment. In order to optimally guide deliberate practice during the active learning exercises and maximally engage student (particularly those who may be struggling) feedback, encouragement and supervision are crucial. To achieve this in a large class more than one person is necessary (Park, 2004). Activities that require higher order thinking and complex problem solving (i.e. "when the going gets tough") will have to be supported by accessible expert feedback (Harland, 2003). GAs were trained by the second author specifically to improve student engagement and higher order thinking. Training consistent of three meetings before the semester to familiarize GAs with Blooms taxonomy (revised), key aspects of active learning and its effectiveness compared to standard lecture formats as well as practice activities. During the semester, GAs and instructor met on Friday of each week to go over events and activities of the past week, the class material for next week, selected activities for the week and practiced every activity as intended for class before implementation. GAs acquired specific content expertise necessary to assist in the course, prepared active learning activities and provided analysis and evaluation of their effectiveness (i.e., reflection) (Aronson, 2011).

\section{Data Sources and Data Analysis}

Data sources included class attendance/participation as assessed by wireless audience response system (i>clicker2); 12 graded assignments of higher order thinking activities (worth 1 point each) completed in flexible groups; and a researcher developed, open ended perception survey (see Appendix 3). The students were randomly assigned to groups and stayed within that group for the duration a given topic was covered (i.e., concept of validity) which could span between 1-3 days and were reassigned to new groups for the next topic. Group assignments were based on student identifiers (i.e., last 4 digits of student ID) and seating charts projected on the screen. The survey was administered in class at the end of the semester. Response rate was 89\% (177 out of 198 students). Class attendance and graded assignments were used to triangulate responses on the perception surveys (Patton, 2015).

The qualitative open-ended survey data was analyzed using an inductive approach (Charmaz, 2006). To analyze the survey data, we organized participant response using the qualitative data software NVivo (QSR, 2015). Using part of the question itself as a starting category (e.g., "What are your perceptions of active learning?" became the category "Student perception of Active Learning"), we organized open-ended student comments. Next, these open-ended comments were coded inductively, moving from more concrete 'open and focus' codes to more abstract 'theme' development (Charmaz, 2006). From this process, three themes emerged from the data: improved higher order thinking skills; benefits and challenges of active learning in large enrollment courses; and fear of failing.

Quantitative data (i.e., student points for activities and attendance) were analyzed to assess differences among race/ethnicities and sample groups via three univariate Analysis of Variance followed by post-hoc pairwise comparison with LSD adjustment and two sided independent sample $t$-tests, respectively. Assumption of normality was checked with Q-Q plots and the Shapiro-Wilk test. Assumption of homogeneity of error variances was assessed with Levene's test. If the assumptions did not hold logarithmic transformation was attempted, or non-parametric analysis of multiple groups (i.e., races/ethnicities) were assessed with the Kruskal-Wallis Test and between groups comparisons were assessed with the Mann-Whitney Test. Simple regression of attendance on class session was used to assess attendance over time and to identify differences among race/ ethnicities by comparing 95\% confidence intervals of unstandardized coefficients. Adjustment of $a$ level for multiple comparison was done by the Bonferroni method were applicable. Level of significance was set a priori at $a=.05$ for all analysis.

Journal of the Scholarship of Teaching and Learning, Vol. 20, No. 1, April 2020.

josotl.indiana.edu 


\section{Results}

This exploratory mixed-methods study showed that across the three race/ethnicity groups, all students perceived that their higher order thinking improved, perceived both benefits and challenges of active learning in large enrollment courses and that throughout the process, they had a fear of failing (see appendix 1).

\section{Improved higher order thinking skills}

Although participants were juniors and seniors, many indicated that this course was the first time they were explicitly taught higher order thinking skills. Participants stated "No [they've never heard of higher order thinking]"; or "Never learned the details of higher order thinking." One student stated "I've never heard of higher order thinking. I'm used to standard lectures". These statements shed light on the lack of explicit attention to higher order thinking strategies and activities these students received in previous courses, regardless of ethnic background. Providing explicit instruction in higher order thinking gives students the tools they need to work in groups in meaningful ways. Because students were taught explicitly, most students regardless of ethnicity, perceived their higher order thinking skills had improved. For the question, "Do you believe your higher order thinking skills have improved? Please explain." One student stated: "I have applied these forms of higher order thinking skills in other classes this semester." Another participant said, "I do [feel that my higher order thinking improved]." "I did feel like I applied the knowledge I acquired towards assignments." Finally, a participant commented that working with others helped. The student stated, "[My higher order thinking skills improved], through partner activities and engaged learning." There were no discernable differences among the Race/ethnicity groups as all perceived they improved their higher order thinking skills in a similar manner and magnitude. This was supported by quantitative assessment of points obtained during the on-line class higher order thinking activities.

Quantitative analysis revealed no significant difference in points earned for activities across race/ethnicities across the sample $\left(F(2,30)=0.648, p=.530, \eta_{p}{ }^{2}=0.04\right)$ with absolute mean differences ranging from 0.3-0.8 points (Figure 1). There was also no significant difference for each race/ethnicity sample compared to the rest of the class i.e. Whites (Medians $=5, U=277.5, p=.663$, $r=0.05$ ), Hispanic/Latino (Medians $=5, U=79.5, p=.667, r=0.08$ ) and Asian (Medians $=6, U$ $=151.5, p=.406, r=0.13)$. 
Figure 1: Mean and SD of points gained in higher order thinking activities.

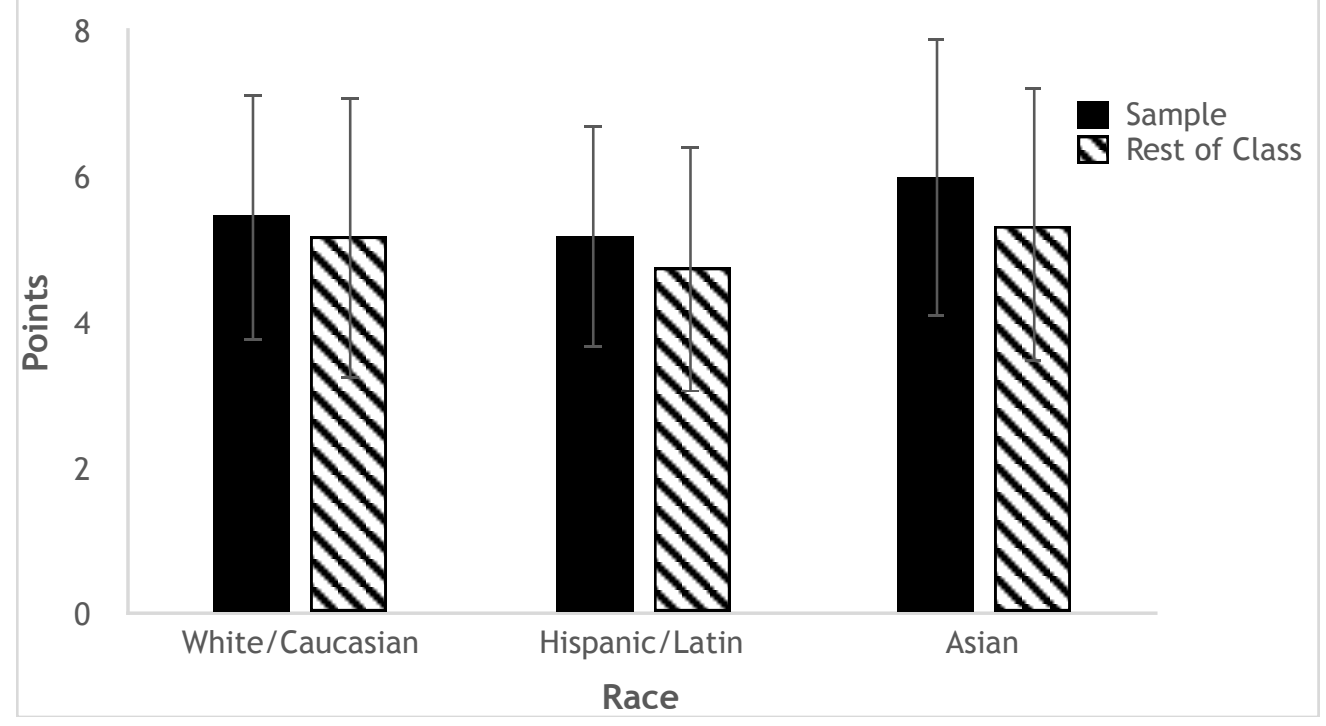

Benefits and Challenges in large enrollment course

Participants also describe benefits and challenges of engaging in higher order thinking skills through active learning activities within a large enrollment course. They stated that some of the challenges included working with unprepared students, not enough time and lack of feedback due to class size. One participant stated, "The size of the class makes getting deeper into concepts and materials difficult." This sentiment was expressed across several students and race/ethnicity in the study. One self-identified Asian male was particularly concerned about active learning in a large lecture setting. He stated, "I understand the purpose of this teaching method, but I believe that to have college students who have been taught another way their entire lives is difficult for us to shift gears. I learn better through the other way of teaching that we are used to. Yes, some students may "memorize" materials without fully understanding but others like myself, memorize and understand at the same time." This student clearly explains the struggle of trying to learn in a different course format. Further, despite the course's focus on Bloom's taxonomy, he believes that "understanding" course material is sufficient.

Participants also felt that at times the course was unorganized because there were so many students moving around getting into "active learning groups." Students were not familiar with moving around and engaging in group work in most of their courses, so it took some getting used to. One student commented: "At times, active learning activities in large lecture hall got a little chaotic and unorganized but I think it's worth the trouble." These sentiments about the benefits and challenges of active learning activities within a large enrollment course were shared across race/ ethnicity groups, and this was again supported by quantitative analysis such as engagement with the course as measured by attendance. Attendance was generally very high (mean $>84 \%$ for all groups, Figure 2). Nevertheless, even at this high level, there was still a significant difference among groups (i.e., no ceiling effect, $\left.\chi^{2}(2, N=75), p=0.15\right)$ with a mean rank of 28 for Whites, 47 for Hispanic/ Latinos and 37 for Asians. There was no significant decline in attendance over the course of the semester for either Whites or Hispanic/Latinos group $(b=-0.2$ to $-0.5, t(24)=-1.30$ to $-1.43, p=$. 165-.207) but attendance did decline for Asians $(b=-1.0, t(24)=-2.80, p=.010)$. On course session 23, attendance dropped for all students and particularly so for Asians. However, there was no significant difference across trends for each group as indicated by overlapping confidence intervals $(-1.20$ to $0.22,-0.62$ to 0.14 and -1.83 to -0.27 for Whites, Hispanic/Latinos, and Asians, respectively). 
Figure 2: Mean attendance for each session across the semester.

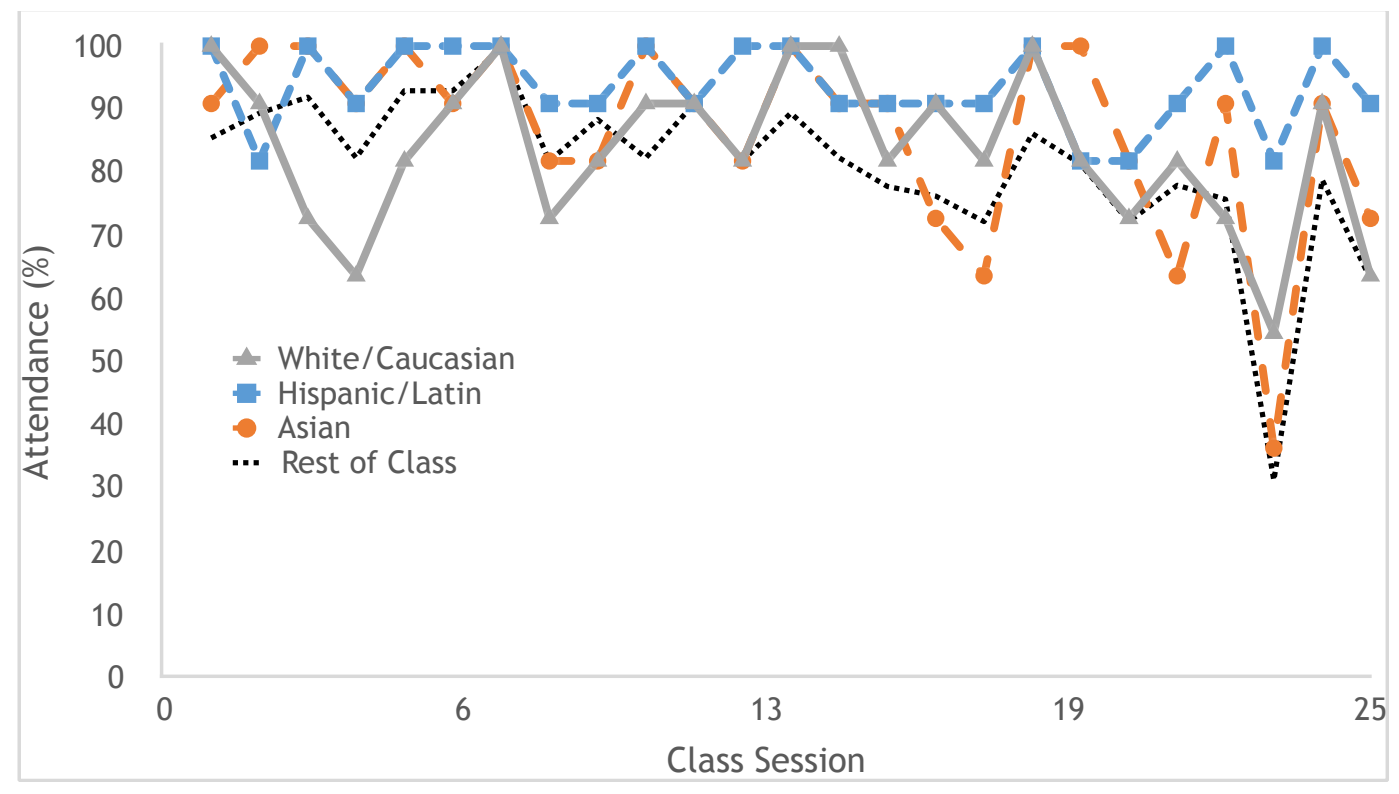

Fear of Failure

The subject of points and how they negatively or positively affect grades came up quite often in these surveys. The active learning activities were completed for extra credit points. Students had a choice whether or not to complete these activities. In this way, students were encouraged to make their own decisions about their level of engagement. For these assignments, participants were concerned about being in "weak" groups, or groups they had to "carry." One participant stated, "I felt I had "carry" my classmates who did not show up or participate." Another student stated, "I didn't like working and depending on random people for some of the in-class assignments."

All participants in this study completed the activities but their reason for doing so mostly focused on the outcome, not the process. Some students stated that they appreciated the effort. "[The professor] is trying hard to change how students learn but that is hard to do when we have been "taught" to learn a certain way for 20+ years." Another student expressed frustration with never having a "right" answer. She stated, "I didn't like how some questions were answered by the professor with another question or with multiple questions. There was no clear answer."

Because of these issues, they were also afraid of failing the class/not passing the final. One student spoke to this, "I just hope I did well enough. Unfortunately, GPA is extremely important for grad school, so I just need an "A" for the class. I will not be evaluated on "what I learned in [this course]." The education system is built this way." All race/ethnicity groups shared this fear and expressed equal concern about their grade.

\section{Discussion}

This exploratory mixed-methods study examined underrepresented and non-underrepresented student perceptions of active learning in a large enrollment STEM course. It illustrates the complexity between integrating best practices in large enrollment STEM courses and the need for high grades so that all students have an opportunity to succeed in post-secondary education. The qualitative data indicated that the majority of participants across groups perceived active learning as Journal of the Scholarship of Teaching and Learning, Vol. 20, No. 1, April 2020. josotl.indiana.edu 
beneficial but challenging in a large class, that their understanding and engagement in higher order thinking skills improved, and that they were very concerned about failing the course. The perceptions of improved higher order thinking skills were shared across all race/ethnicity groups, and the quantitative analysis supports this notion. All race/ethnicities showed similar achievement in higher order thinking activities, demonstrating wide applicability of this approach. This is of note because while lecture only approaches are ineffective for most students (Freeman et al., 2014; Wieman, 2007; Zoller, 1993), they are particularly ineffective for diverse students in large lecture classes with a reputation for high failure rates such as is often the case in many STEM courses (Haak et al., 2011; Hrabowski, 2011; Mervis, 2010). Thus, this approach provides an avenue for all students to engage in cognitively challenging concepts in critically meaningful ways. While it was beyond the scope of this study to objectively assess higher order thinking skills with a standardized, validated instrument, this outcome is nevertheless highly encouraging because students are capable of accurately reporting their own learning (Chesebro \& McCroskey, 2000; Smith \& Cardaciotto, 2012). In addition, their perceptions have the potential to influence learning outcomes (Lizzio et al., 2002; Smith \& Cardaciotto, 2012). Indeed, students that perceive that their higher order thinking skills are improving are more likely to persist in engaging the skill than those that do not believe they are improving.

Other studies have also shown that, across all groups, purposeful and persistent practice of higher order thinking enhances these skills, the disposition to use them and their self-confidence (Miri et al., 2007; Nelson \& Crow, 2014; Nguyen, 2016). In addition to similar achievement, engagement was also consistent across race/ethnicity with students from all assessed groups showing high levels of engagement (as assessed by attendance) with Hispanic/Latino students attending most regularly. As mentioned in the results, there was a noticeable but none significant drop in attendance during course session 23. This day was announced to be a specific "question and answer" session and did not involve activities for points which likely lowered attendance and participation rates. This is meaningful because it suggests that students may have been trained to attend class only if it affects their grade. This would indicate low internal motivation for attending class. If this data point is removed, then there is no more significant change in attendance over the course at the adjusted $\alpha$-level. The qualitative data also supports this finding as students across race/ ethnicity stated their frustration with the point system for the extra credit active learning activities. Students engaged in the extra credit activities to boost their grades because academic incentive structures value numerical indicators of improvement more than qualitative indicators. This is an important consideration given that problems can arise after initial implementation of active learning strategies when over the course of a week student perceptions become less favorable (McDougall, 2013). Based on the attendance data we did not observe such a tendency. This was in spite of the fact that students usually resent having to expend intellectual effort (Smith \& Cardaciotto, 2012) without consistent, tangible reinforcements.

\section{Implications and Recommendations for Practice}

The current study extends the knowledge of active learning and examines the effects of best practice into a large, upper level undergraduate course with underrepresented students. A proper college education must go beyond mere knowledge acquisition and skill development in a specific discipline. This notion is not just philosophical but supported by stakeholders such as employers who expect students to gain proficiencies in non-material specific areas such as team work and higher order thinking (Hart Research Associates, 2015). In fact, a recent study of over 400 employers who hire a large percentages of college graduates indicates that more employers ( 25 vs. $15 \%$ ) believe that long term career success depends on general knowledge and skills rather than knowledge and skills of a specific field or position (Hart Research Associates, 2015). This is contrary

Journal of the Scholarship of Teaching and Learning, Vol. 20, No. 1, April 2020.

josotl.indiana.edu 
to the popular tendencies for colleges and university to emphasis 'job readiness,' and career focused/ specific training (Brand \& Valent, 2013; Docherty, 2014; Fein, 2017). The highest valued learning outcomes by these employers include oral and written communication skills, teamwork, decision making, critical thinking and application of knowledge, analysis, evaluating information, innovation/ creativity numeracy and solving problems with people from different backgrounds (Hart Research Associates, 2015). One cannot help but notice that this list is almost entirely opposite to standard lecture based education in large classes where isolated, individual information memorization is the predominant style of learning and passivity abounds (Baldwin, 2009; Brainard, 2007; National Research Council, 2003). Despite the obvious antithesis of a standard, large, lecture course format to these desired learning outcomes STEM education is still dominated by this type of instruction (Stains, 2018). Also of note is that these desired learning outcomes are heavily weighted towards the higher rungs of Bloom's taxonomy of higher order thinking.

\section{Recommendations regarding 'Improved higher order thinking skills'}

Going forward, one can build on the positive perceptions expressed by students regarding engagement in active learning for higher order thinking. One should highlight the importance of these skills and how to achieve them. We provided students with detailed explanations on what these skills are using Bloom's taxonomy. We also highlighted how these skills are valued by key stakeholders such as employers. We emphasized higher order thinking as a targeted student learning outcome for the course as well as outlined which specifics skills where targeted with each activity.

\section{Recommendations regarding 'Benefits and Challenges in large enrollment course'}

The challenges expressed by students are difficult to overcome. Students were randomly assigned to groups as research has shown the benefits of heterogeneous groups, but most of the participants felt this was problematic. Problems such as students being unprepared or unwilling to contribute sufficiently to group activities were commonly expressed. Strategies to rectify this issue include assessments prior to engaging students in activities. Readiness assurance testing such as employed in team based learning formats offer one such option, and several approaches have been described (Antoun, J., Nasr, R., \& Zgheib, N. K., 2015). Individual contributions to collaborative group activities are difficult to monitor in large classroom environments. Peer evaluation is likely the most feasible solution to this issue. Recently, a combined analytical mapping approach requiring minimal computational effort has been developed which allows for reliable individual grade assignment based on peer marks (Dijkstra et al., 2016; Spartar et al., 2015). We aim to investigate the incorporation of these strategies in future interactions of similar courses.

Further challenges such as the unfamiliarity of active learning may actually present a desirable learning opportunity. A certain level of uncomfortableness will likely be unavoidable when employing active learning for higher order thinking. Requiring student to step out of their comfort zone and engage in an unfamiliar activity is an important learning outcome in and of itself. Ideally, this can be done without introducing undue anxiety (Cooper, 2018). However, one should be cognizant and empathetic to student perceptions by being transparent in expectations and explicit in direction. Further, it is likely prudent to first engage in activities that more heavily rely on the lower levels of Bloom's to carefully scaffold the progression to higher levels in order to aid in the transition to the new format and way of thinking (Vygotsky, 1980).

Organizational issues perceived by students could be resolved with a simple training session at the beginning of the course. Group assignments were based on student identifiers and seating charts projected on the screen. Students were expected to easily transition to new groups at the beginning of each class. We did not anticipate that this would present a challenge to upper division

Journal of the Scholarship of Teaching and Learning, Vol. 20, No. 1, April 2020.

josotl.indiana.edu 
students. In the future, a simple training sessions where students will be asked to find their groups quickly and efficiently several times with several different arrangements could likely alleviate much of this issue. We can envision a 'fun challenge' where students successfully try to improve the time it takes to arrange themselves into the appropriate groups based on varying the overhead display. After a few such practice runs, we would expect students will become highly efficient in the desired transition.

\section{Recommendations regarding Fear of Failure'}

The issue of fear of failing is a difficult one to resolve. It was not dependent on students fearing that they were unable to learn from the activities. Rather, it is to students worrying that they would not be rewarded with a high grade. An obvious solution would be to remove all points associated with the activities, but this may be counterproductive. Participation seemed to (in part) depend on the points attached to the activities. Therefore assigning fewer or no points would likely result in reduced participation. On the other hand, increasing the points allocated to the activities could further increase uncertainty and anxiety as this was already the case with just assigning extra credit points. A potential solution could be to allow more space for 'failure' while keeping incentives for participation. One such strategy is to only count a certain number of activities towards the course grade (e.g., the ten activities with the highest scores). As students do not know beforehand which activities they will get graded on and how high their score will be, this should reduce the stakes and still provide an incentive for participation. Concomitantly, being assigned to a 'weak' or poorly performing group would hopefully be perceived less impactful as activities from such days will likely not factor into the top ten scores. Lastly, perceived discomfort of not having clear cut, single solution answers is again an issue that is understandable but likely unavoidable. Clear cut, single solutions are nice and comforting but simply do not represent the real world, especially not for issues that require higher order thinking. While one should be aware of and empathize with students concerns, one should not shy away from exposing them to uncertainty or a multitude of possible solutions to any given problem if one cares to prepare students for more than taking simple examinations.

\section{Conclusion}

Active learning specifically targeted to higher order thinking was equally effective in engaging underrepresented as non-underrepresented students in this large enrollment STEM course (i.e., Measurement and Evaluation in Kinesiology). It also improved students' self-assessed higher order thinking skills. Clear definitions of higher order thinking and transparency regarding focus, importance, and impact of these skills were perceived as important elements for successful implementation by these students. Several challenges were perceived equally amongst students from all backgrounds regarding peer performance in group activities, organization difficulty due to class size, unfamiliarity of active learning approaches and grade pressures. Strategies addressing these challenges such as peer evaluation, organizational practice, progressive transition of activities and alternative grading strategies present promising targets for future investigations.

\section{Declaration of Conflicting Interests}

The author(s) declared no potential conflicts of interest with respect to the research, authorship, and/or publication of this article. 


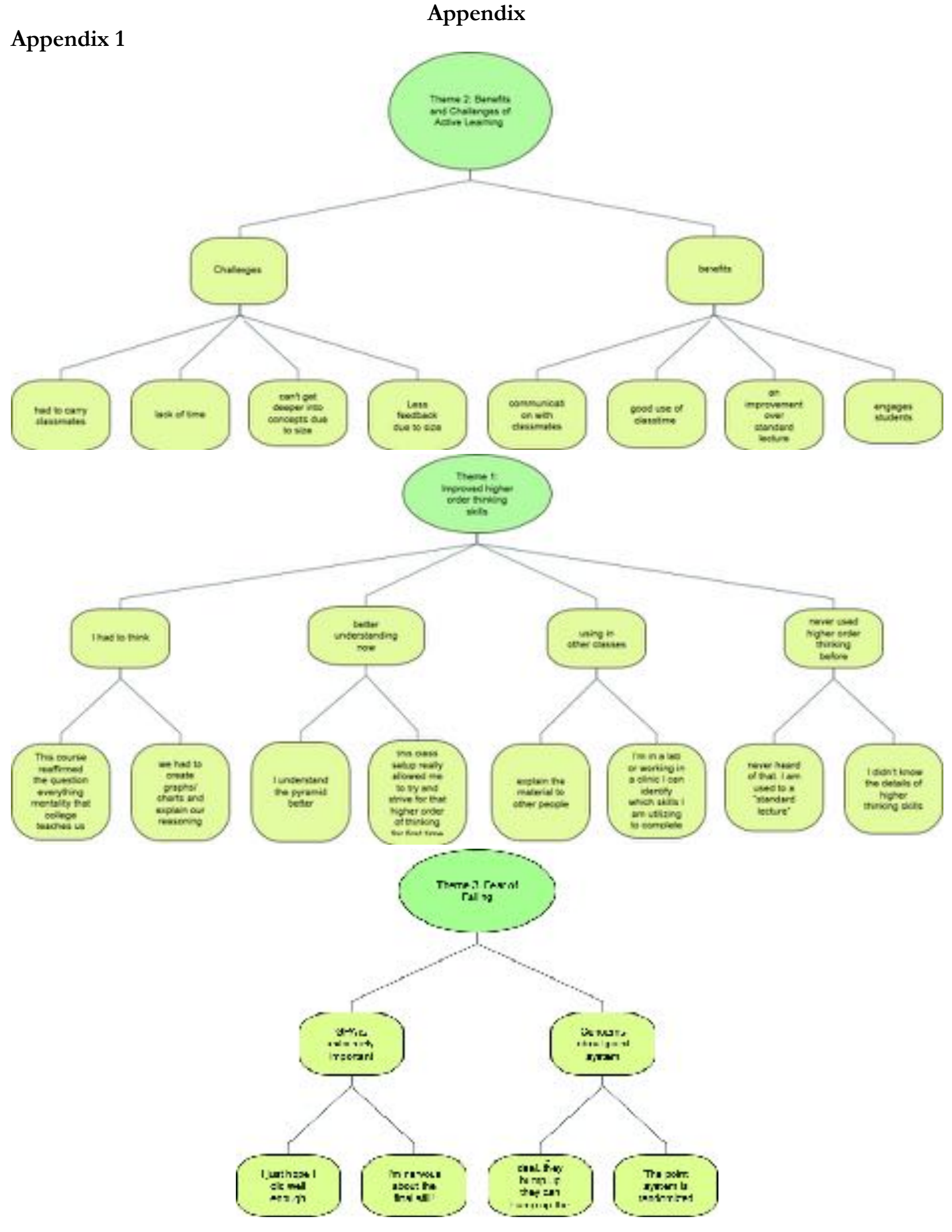

Journal of the Scholarship of Teaching and Learning, Vol. 20, No. 1, April 2020. josotl.indiana.edu 


\section{Appendix 2}

Activities were submitted for grading, and 1 point was awarded when activity specific criteria (outlined in examples below) were met. Each activity was worth 1 point. Total number of graded activities was 16.

Example of higher order thinking activity (early semester):

Students were tasked with applying terminology explained in the online lecture to a preset schematic on how grades are awarded at the University. Students were further tasked with evaluating whether this process makes sense to them in light of the concepts explained in the online lecture and discussed in class. The concepts of higher order thinking according to Bloom's taxonomy had been explained to students previously, and they were reminded and made aware of what type of thinking they were expected to perform for the activity (i.e., application, analysis, and evaluation). Students submitted their activity at the end of class. A point was awarded if the schematic was filled in correctly and if the written evaluation included discussion of issues regarding interconversion of continuous with discrete scores and ordinal with interval/ratio scales as well as a final position (irrespective of whether it was positive or negative).

\section{How do you get graded?}

- Fill in:

- GPA (G), Letter Grade (L), raw Points on test (P), \% grade

- Continuous vs. discrete

- Conversion

- Type of Scale

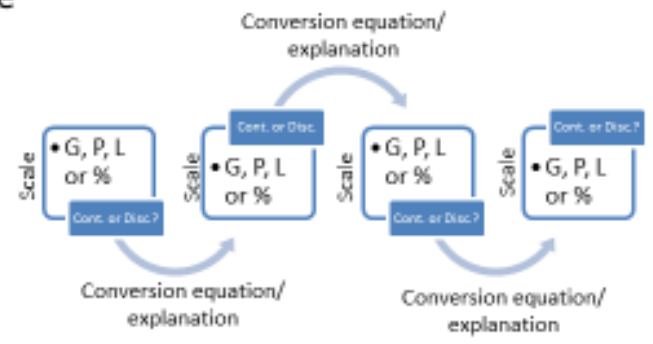

- Evaluate whether this process makes 'sense' to you.

Example of higher order thinking activity (mid-semester):

Students were task to analyze data they had previously collected regarding different types of error applying simple, common analysis techniques such as correlation coefficients and scatter plots with trend lines. Students were further instructed to use these techniques evaluate the key measurement concepts of validity, culminating in the decision to either accept or reject their measurement. Students were also instructed to identify what type of higher order thinking they needed of accomplish this task. A point was awarded correct results and graphs were produced and

Journal of the Scholarship of Teaching and Learning, Vol. 20, No. 1, April 2020. josotl.indiana.edu 
appropriately discussed to support the final conclusion of whether or not the to accept the measurement.

\section{Submit}

- Raw data

- Graph

- Scatterplot

- R, R2

- Trend line with equation

- Short answer:

- What does scatter plot show (wide, narrow, ceiling/flooring)?

- What is the relationship of $x$ and $y$ (with units)?

- How close/strong is the association between $x$ and $y$ ?

- How valid is 'your measure' compared to the 'criterion measure'?

- What evidence did you base your decision on?

- Would you accept this measurement? Why?

- What type of thinking/learning did you just do?

- Hint: think what a perfectly valid relationship would look like

Example of higher order thinking activity (late-semester):

As part of a multi-sectional exploration of the key components of study designs students were tasked to create an intervention, apply their knowledge of sample selection considerations, create sample selection criteria and evaluate their criteria. A point was awarded if the intervention was suitable for study, sample selection criteria were clearly outlined, and the explanation included appropriate discussions of the pros and cons of the criteria.

Journal of the Scholarship of Teaching and Learning, Vol. 20, No. 1, April 2020.

josotl.indiana.edu 


\section{Activity-Sample selection}

- By yourself, pair, group

- Create an intervention for a study in your area of interest

- Identify extremes of sample selection - E.g. highest external validity vs. largest potential effect

- Provide appropriate sample selection criteria to best balance sample for your intervention

- Explain your sample selection and why it is best that way 


\section{Appendix 3}

\section{Informed Consent}

Dear Student in ENS 305 Spring 2016,

This study is being conducted by Jochen Kressler, PhD, an assistant professor in the Exercise and Nutritional Science Department at SDSU and Benikia Kressler, PhD, assistant professor in the College of Education at CSU Fullerton. The aim of this study is to identify student perceptions of the course ENS 305 Measurement and Evaluation in Kinesiology for the spring 2016 semester. The course was redesigned for the spring 2016 semester to use I) a flipped format, II) a mastery learning progression approach and III) data based decision making to target instruction.

You are being asked to complete a survey because you are a student in the course. The results will be used as formative assessment to improve the course and potentially reported in an education journal.

The following survey includes questions that ask you to describe your perception of the course and instructor. The survey also includes questions about your demographic background. It will take about 30 minutes of your time to complete the survey.

Your participation in this study is voluntary. If you decide to participate, your responses will be confidential - that is, recorded without any identifying information that is linked to you. You will gain one point of extra credit for completing the survey. If you choose not to participate you will have the choice to engage in an alternative activity that will also include a one point extra credit opportunity.

If you have any questions regarding this survey, please contact Benikia Kressler at 657-278-3760.

\section{Signing the consent form}

I have read (or someone has read to me) this form and I am aware that I am being asked to participate in a research study. I have had the opportunity to ask questions and have had them answered to my satisfaction. I voluntarily agree to participate in this study.

I am not giving up any legal rights by signing this form. I will be given a copy of this form.

\section{Printed name of participant}

\section{Signature of participant}

Date and time 


\section{1) Demographics}

a. Age in years:

b. Gender identity:

c. Ethnicity/Race:

d. Father's highest level of education (circle one):

less than high school high school some college college graduate

e. Mother's highest level of education:

less than high school high school some college college graduate

f. First generation college student: (circle one)? YES NO

g. Is English your first language (circle one)? YES NO

h. Current year in college (circle one): Freshman Sophomore Junior Senior

Major:

Emphasis: 


\section{DIRECTIONS: PLEASE ANSWER THE QUESTIONS BELOW HONESTLY AND TO YOUR BEST ABILTYY}

\section{2) Perception of Course}

a. What are your thoughts on active learning activities within the large lecture hall format? Please explain why.

b. What are your perceptions of having the lectures online rather than in class? Please explain why.

c. Are there other things in this course that you enjoyed? Please explain why. 
DIRECTIONS: PLEASE ANSWER THE QUESTIONS BELOW HONESTLY AND TO YOUR BEST ABILITY

d. Are there other things that you didn't like? Please explain why.

\section{3) Higher Order Thinking Skills}

a. Before ENS 305, did you know what higher order thinking skills were?

b. Do you believe your higher order thinking skills have improved? Please explain.

Journal of the Scholarship of Teaching and Learning, Vol. 20, No. 1, April 2020.

josotl.indiana.edu 
DIRECTIONS: PLEASE ANSWER THE QUESTIONS BELOW HONESTLY AND TO YOUR BEST ABILITY

\section{5) Final Question}

a. Do you think you got your "money's worth" in this course (and/or stakeholder's money's). Please explain why or why not.

THANK YOU FOR YOUR FEEDBACK!!

Journal of the Scholarship of Teaching and Learning, Vol. 20, No. 1, April 2020.

josotl.indiana.edu 


\section{References}

Ali, F. (2017). Global competitiveness report 2017-2018. Retrieved from http://www3.weforum.org/docs/GCR2017-2018/05FullReport/ TheGlobalCompetitivenessReport2017\%E2\%80\%932018.pdf

Anderson, L. W., Krathwohl, D. R., Airasian, P. W., Cruikshank, K. A., Mayer, R. E., Pintrich, P. R., ... \& Wittrock, M. C. (2001). A taxonomy for learning, teaching, and assessing: A revision of Bloom's taxonomy of educational objectives, abridged edition. White Plains, NY: Longman.

Antoun, J., Nasr, R., \& Zgheib, N. K. (2015). Use of technology in the readiness assurance process of team based learning: paper, automated response system, or computer based testing. Computers in Human Behavior, 46, 38-44.

Aronson, L. (2011). Twelve tips for teaching reflection at all levels of medical education. Medical Teacher 33(3): 200-205. DOI: 10.3109/0142159X.2010.507714

Baldwin, R. G. (2009). The climate for undergraduate teaching and learning in STEM fields. New Directions for Teaching and Learning, 117, 9-17.

Bean, J. C. (2011). Engaging ideas: The professor's guide to integrating writing, critical thinking, and active learning in the classroom: John Wiley \& Sons.

Biggs, J. B. (2011). Teaching for quality learning at university: What the student does. McGrawHill Education (UK).

Bligh, D. A. (1998). What's the use of lectures? Exeter, England: Intellect books.

Bok, D. (2009). Our underachieving colleges: A candid look at how much students learn and why they should be Learning More. Princeton, New Jersey: Princeton University Press.

Bonwell, C. C. \& Eison, J. A. (1991). Active Learning: Creating Excitement in the Classroom. ASHE-ERIC Higher Education Reports No. 1. Washington, D.C.

Braga, M., Paccagnella, M., \& Pellizzari, M. (2014). Evaluating students' evaluations of professors. Economics of Education Review 41, 71-88.

Brainard, J. (2007). The tough road to better science teaching. Chronicle of Higher Education 53(48), A16.

Brand, B. \& Valent, A. (2013). Improving college and career readiness for students with disabilities. College and Career Readiness and Success Center.

Carrell, S. E. \& West, J. E. (2010). Does professor quality matter? Evidence from random assignment of students to professors. Journal of Political Economy, 118(3), 409-432.

Casagrand, J. \& Semsar, K. (2017). Redesigning a course to help students achieve higher-order cognitive thinking skills: from goals and mechanics to student outcomes. Advances in Physiology Education, 41(2), 194-202.

Casner-Lotto, J. \& Barrington, L. (2006). Are they really ready to work? Employers' perspectives on the basic knowledge and applied skills of new entrants to the 21 st century US workforce. Partnership for $21^{\text {st }}$ Century Skills. 1 Massachusetts Avenue NW Suite 700, Washington, DC 20001.

Charmaz, K. (2006). Constructing grounded theory: A practical guide through qualitative analysis. London; Thousand Oaks, Calif.: Sage Publications.

Chesebro J.L \& McCroskey JC (2000). The relationship between students' reports of learning and their actual recall of lecture material: A validity test.

Cooper, K. M., Downing, V. R., \& Brownell, S. E. (2018). The influence of active learning practices on student anxiety in large-enrollment college science classrooms. International Journal of STEM Education, 5(1), 23.

Creswell, J. W., Plano, C., Gutmann, M. L., \& Hanson, W. E. (2003). Advanced mixed methods research designs. Handbook of Mixed Methods in Social and Behavioral Research 209: 240.

Journal of the Scholarship of Teaching and Learning, Vol. 20, No. 1, April 2020.

josotl.indiana.edu 
Dede, C. (2010). Comparing frameworks for 21 st century skills. 21st Century Skills: Rethinking how Students Learn 20: 51-76.

Dijkstra, J., Latijnhouwers, M., Norbart, A., \& Tio, R. A. (2016). Assessing the "I" in group work assessment: State of the art and recommendations for practice. Medical teacher, 38(7), 675-682.

Docherty, D. (2014). Universities must produce graduates who are ready for any workplace. The Guardian.

Dunkin, M. J. (1983). A review of research on lecturing. Higher education research and development, 2(1), 63-78.

Dunkin, M. J. (1990). Willingness to obtain student evaluations as a criterion of academic staff performance. Higher Education Research and Development, 9(1), 51-60.

Eichler, J. F. \& Peeples, J. (2016). Flipped classroom modules for large enrollment general chemistry courses: a low barrier approach to increase active learning and improve student grades. Chemistry Education Research and Practice, 17(1): 197-208.

Fein, P. (2017). Better Marriage between College and Job Training. Inside Higher Ed.

Freeman, S., Eddy, S. L., McDonough, M., Smith, M. K., Okoroafor, N., Jordt, H., et al. (2014). Active learning increases student performance in science, engineering, and mathematics. Proceedings of the National Academy of Sciences of the United States of America, 111(23), 8410-8415.

Gasiewski, J. A., Eagan, M. K., Garcia, G. A., Hurtado, S., \& Chang, M. J. (2012). From gatekeeping to engagement: A multicontextual, mixed method study of student academic engagement in introductory STEM courses. Research in Higher Education, 53(2): 229-261.

George, M. D. \& Bragg, S. (1996). Shaping the future: New expectations for undergraduate education in science, mathematics, engineering, and technology. DIANE Publishing.

Ghaffarzadegan, N., Hawley, J., \& Desai, A. (2014). Research workforce diversity: The case of balancing national versus international postdocs in US biomedical research. Systems Research and Behavioral Science, 31(2), 301-315.

Gutwill-Wise, J. P. (2001). The impact of active and context-based learning in introductory chemistry courses: An early evaluation of the modular approach. J.Chem.Educ, 78(5), 684.

Haak, D. C., HilleRisLambers, J., Pitre, E., \& Freeman, S. (2011). Increased structure and active learning reduce the achievement gap in introductory biology. Science, 332(6034), 1213-1216.

Harland, T. (2003). Vygotsky's zone of proximal development and problem-based learning: Linking a theoretical concept with practice through action research. Teaching in Higher Education, 8(2), 263-272.

Harris, R. P., Helfand, M., Woolf, S. H., Lohr, K. N., Mulrow, C. D., Teutsch, S. M., et al. (2001). Current methods of the US preventive services task force: a review of the process. American Journal of Preventive Medicine, 20(3), 21-35.

Hart Research Associates. (2015). Falling Short? College Learning and Career Success. Connecticut Avenue, NW Washington, DC. Retrieved from https://www.aacu.org/sites/ default/files/files/LEAP/2015employerstudentsurvey.pdf

Hrabowski, F. A. (2011). Boosting minorities in science. Science, 331(6014), 125.

Kornell, N. \& Hausman, H. (2016). Do the best teachers get the best ratings? Frontiers in Psychology, 7, 570.

Lizzio, A., Wilson, K., \& Simons, R. (2002). University students' perceptions of the learning environment and academic outcomes: implications for theory and practice. Studies in Higher Education, 27(1), 27-52.

LoPresto, M. C. \& Slater, T. F. (2016). A new comparison of active learning strategies to traditional lectures for teaching college astronomy. Journal of Astronomy and Earth Sciences Education, 3(1), 59.

Lou, Y., Abrami, P. C., \& Spence, J. C. (2000). Effects of within-class grouping on student

Journal of the Scholarship of Teaching and Learning, Vol. 20, No. 1, April 2020.

josotl.indiana.edu 
achievement: An exploratory model. The Journal of Educational Research, 94(2), 101-112.

Lumpkin, A., Achen, R. M., \& Dodd, R. K. (2015). Using technology-nested instructional strategies to enhance student learning. InSight: A Journal of Scholarly Teaching, 10, 114-125.

Maddux, W. W., Bivolaru, E., Hafenbrack, A. C., Tadmor, C. T., \& Galinsky, A. D. (2014). Expanding opportunities by opening your mind: Multicultural engagement predicts job market success through longitudinal increases in integrative complexity. Social Psychological and Personality Science, 5(5), 608-615.

Mayer, R. E., Stull, A., DeLeeuw, K., Almeroth, K., Bimber, B., Chun, D., et al. (2009). Clickers in college classrooms: Fostering learning with questioning methods in large lecture classes. Contemporary Educational Psychology, 34(1), 51-57.

Mazur, E. (2011). Memorization or understanding: Are we teaching the right thing? Waterloo, ON, Canada, University of Waterloo.

McDougall, D. A. (N/A). Doc's Flipped Classroom. http:/ / docsflippedclassroom.weebly.com/

Mervis, J. (2010). Undergraduate science. Better intro courses seen as key to reducing attrition of STEM majors. Science, $330(6002), 306$.

Miri, B., David, B., \& Uri, Z. (2007). Purposely teaching for the promotion of higher-order thinking skills: A case of critical thinking. Research in Science Education, 37(4), 353-369.

Mulligan, D., \& Kirkpatrick, A. (2000). How much do they understand? Lectures, students and comprehension. Higher Education Research \& Development, 19(3), 311-335.

Nail, R. (2012). Education is undergoing a startling revolution — Let's support it! Forbes, Retrieved from https://www.forbes.com/sites/singularity/2012/06/27/education-isundergoing-a-startling-revolution-lets-support-it/\#75b0ece351 ea

National Research Council. (2003). Evaluating and Improving Undergraduate Teaching in Science, Technology, Engineering, and Mathematics. National Academies Press.

Nelson, L. P. \& Crow, M. L. (2014). Do active learning strategies improve students' critical thinking? Higher Education Studies, 4(2), 77-90.

Nguyen, B., Yu, X., Japutra, A., \& Chen, C. S. (2016). Reverse teaching: Exploring student perceptions of "flip teaching". Active Learning in Higher Education, 17(1), 51-61.

Nguyen, T. T. B. (2016). Critical thinking in a Vietnamese tertiary English as a foreign language context: Current practices and prospects. (Doctoral dissertation).

Park, C. (2004). The graduate teaching assistant (GTA): Lessons from North American experience. Teaching in Higher Education, 9(3), 349-361.

Patton, M. Q. (2015). Qualitative research \& evaluation methods: Integrating theory and practice. Thousand Oaks, CA: Sage Publications, Inc.

Ryan, J. J., Anderson, J. A., \& Birchler, A. B. (1980). Student evaluation: The faculty responds. Research in Higher Education, 12(4), 317-333.

Saavedra, A. R., \& Opfer, V. D. (2012). Learning 21st-century skills requires 21 st-century teaching. Phi Delta Kappan, 94(2), 8-13.

Sellami, N., Shaked, S., Laski, F. A., Eagan, K. M. \& Sanders, E. R. (2017). Implementation of a learning assistant program improves student performance on higher-order assessments. CBE Life Sciences Education, 16(4), 10.1187/cbe.16-12-0341.

Smith, C. V. \& Cardaciotto, L. (2012). Is active learning like broccoli? Student perceptions of active learning in large lecture classes. Journal of the Scholarship of Teaching and Learning 11(1), 53-61.

Spatar, C., Penna, N., Mills, H., Kutija, V., \& Cooke, M. (2015). A robust approach for mapping group marks to individual marks using peer assessment. Assessment \& Evaluation in Higher Education, 40(3), 371-389. 
Stains, M., Harshman, J., Barker, M. K., Chasteen, S. V., Cole, R., DeChenne-Peters, S. E., ... \& LevisFitzgerald, M. (2018). Anatomy of STEM teaching in North American universities. Science, 359(6383), 1468-1470.

US Department of Education. (2014). Graduation rates of first-time, full-time bachelor's degree seeking students at 4-year postsecondary institutions, by race/ethnicity, time to completion, sex, and control of institution: Selected cohort entry years, 1996 through 2006. Retrieved from https://nces.ed.gov/programs/digest/d13/tables/dt13 326.10.asp

Uttl, B., White, C. A., \& Gonzalez, D. W. (2017). Meta-analysis of faculty's teaching effectiveness: Student evaluation of teaching ratings and student learning are not related. Studies in Educational Evaluation, 54, 22-42.

Vygotsky, L. S. (1980). Mind in society: The development of higher psychological processes. Harvard university press.

Webb, N. M. (1980). An analysis of group interaction and mathematical errors in heterogeneous ability groups. British Journal of Educational Psychology, 50(3), 266-276.

White, P. J., Larson, I., Styles, K., Yuriev, E., Evans, D. R., Rangachari, P. K., ... \& Eise, N. (2016). Adopting an active learning approach to teaching in a research-intensive higher education context transformed staff teaching attitudes and behaviours. Higher Education Research \& Development, 35(3), 619-633.

Wieman, C. (2007). Why not try a scientific approach to science education? Change: The Magazine of Higher Learning, 39(5), 9-15.

Winkelmes, M. A. (2013). Transparency in teaching: Faculty share data and improve students' learning. Liberal Education, 99(2), n2.

Winkelmes, M., Bernacki, M., Butler, J., Zochowski, M., Golanics, J., \& Weavil, K. (2016). A teaching intervention that increases underserved college student's success. Peer Review, 18(1/2) Retrieved from https://www.aacu.org/peerreview/2016/winter-spring/Winkelmes

Zoller, U. (1993). Are lecture and learning compatible? Maybe for LOCS: Unlikely for HOCS. Journal of Chemical Education, 70(3), 195. 